When Knowledge is Blinding:

The Dangers of Being Certain About the Future During Uncertain Societal Events Irmak Olcaysoy Okten $^{1^{*}} \quad$ Anton Gollwitzer ${ }^{2} \quad$ Gabriele Oettingen ${ }^{1}$

${ }^{1}$ Department of Psychology, New York University, New York, NY, USA

${ }^{2}$ Department of Psychology, Yale University, New Haven, CT, USA

********THE FOLLOWING CONTENT HAS NOT BEEN PEER REVIEWED******** IF YOU REFERENCE THIS ARTICLE IN ANY FORM PLEASE INDICATE THAT IT HAS NOT BEEN PEER REVIEWED- THANK YOU

Author Note: All verbatim material files and data files can be found here:

https://osf.io/sbqkp/?view_only=eff9d85268594e6eaf16e60cc931030e 


\begin{abstract}
Past research has independently examined the concepts of certainty and future thought. Here we combine these concepts by examining the cognitive and behavioral outcomes of certainty about the future during periods of societal uncertainty. Three studies $(N=1218)$ examined future certainty, defined as feeling certain about some future event or outcome, during two major societal events - the COVID-19 pandemic and the 2020 U.S. Presidential Election. In Study 1, certainty about positive or negative futures of COVID-19 (e.g., the pandemic will end soon; the pandemic will never end) predicted poorer information processing-ignorance of medical experts, adherence to conspiratorial thinking, and lower objective knowledgeability about COVID-19. Building on these findings, in Study 2, future certainty predicted antisocial health behaviors, including failing to social distance. Study 3 extended these findings to the political domain - the 2020 Presidential Election. Future certainty that one's preferred candidate would win the election predicted poor information processing and antisocial behaviors in terms of claiming that the election was rigged, endorsing violence if one's candidate lost, and, among Trump supporters, identifying with Capitol insurrectionists. These findings introduce future certainty as a psychological phenomenon linked to intellectual blindness and antisocial behaviors during important periods of societal uncertainty.
\end{abstract}

Keywords: subjective certainty, future thinking, COVID-19, elections, information processing, uncertainty 


\section{When Knowledge is Blinding: The Dangers of Being Certain About the Future During Uncertain Societal Events}

Predicting the future is a highly regarded human faculty. As noted previously (Bandura 1977; Mischel, 1973; Oettingen, 2012), beliefs about the future can be surprisingly accurate when based on past or present experiences (Mellers et al., 2015). For example, relying on statistical information, people can accurately predict weather trends and outcomes of sports events (e.g., Martino, 2003). Still, many times, and especially when relevant data or past experiences are unavailable, as is the case during unexpected events (e.g., an unforeseen pandemic), predictions may fail. As Plato wrote, beliefs are, of course, fallible (see Santas, 1990), and the future is technically unknowable.

Though the future is often uncertain, people may sometimes feel certain about future events. Such felt knowledge is apparent in linguistic phrases, for instance, claiming that something "will definitely" happen or that one has "no doubt" about a specific unknown future (Simon-Vandenbergen \& Aijmer, 2008). Despite people's apparent willingness to adopt certainty about the future, past work has largely investigated certainty and future thought independently. Research has, for instance, examined attitudinal certainty (e.g., Petty \& Krosnick, 1995, Skitka, 2010) and unfounded certainty (e.g., Burton, 2008; Gollwitzer \& Oettingen, 2019). At the same time, studies have examined future thought (e.g., predictions, expectations) in relation to decision making (e.g., Gilbert \& Ebert, 2002), motivation (e.g., behavior change; Oettingen, 2012), and affect (e.g., future pessimism and depression, e.g., Miranda \& Mennin, 2007). Here, we combine these two research areas — certainty and future thought — to introduce subjective certainty about future events (hereafter referred to as "future certainty") as a psychological phenomenon. To do so, we examined the potential detrimental cognitive and behavioral 
outcomes of future certainty during two societal events of uncertainty - the COVID-19 pandemic and the 2020 U.S. Presidential Election. Given the lack of available information and people's desire for information and knowledge during these uncertain events (e.g., Hofstede, 1991; Kruglanski \& Orehek, 2012), future certainty should play a particularly important role in individuals' cognition and behavior in these contexts.

\section{Future Certainty vs. Beliefs}

Certainty about the future differs from holding beliefs about the future-defined here as having predictions about the future with some doubt. For one, certainty corresponds to a state of "knowing," which includes greater mental rigidity and confidence than the state of "believing" (e.g., DeRose, 2009; p. 186). Unlike beliefs held with doubt that can be updated in a Bayesian sense in response to new information, knowledge or certainty is not impacted by, and may even increase, in response to counter-information (Petty \& Krosnick, 1995). Additionally, while beliefs are typically informed by experiences and facts (Bandura, 1977; Mischel, 1973; Oettingen, 2012), certainty or "felt-knowledge" is often informed by one's desires and wishes, and is less founded in one's experience and reality (Gollwitzer \& Oettingen, 2019). Taken together, future certainty should operate as a rigid mental state that is distinct from holding beliefs about the future, and in turn, have unique cognitive and behavioral consequences.

\section{Potential Outcomes of Future Certainty}

Future certainty should impact how people think and act in the present, including whether people adapt or regulate their behavior, and how they plan for the future (e.g., Chignell, 2021; Oettingen, 2012; Oettingen \& Chromik, 2018). Below, we outline two potential consequences of future certainty during uncertain societal events: poor information processing (cognition) and antisocial actions (behavior). We selected these outcomes due to their relevance to the societal 
periods of uncertainty examined here - the COVID-19 pandemic and the 2020 Presidential Election. Poor information processing regarding COVID-19, such as accepting COVID-19 misinformation, and antisocial noncompliance behavior, such as refusing to wear a mask or social distance, were major societal problems during the COVID-19 pandemic (e.g., Gollwitzer et al., 2020; Northington et al., 2021; Roozenbeek et al., 2020). Regarding the 2020 Election, unfounded election fraud claims spread like wildfire after the election, leading to the violence witnessed at the Capitol on January 6 ${ }^{\text {th }}, 2021$ (e.g., Abilov et al., 2021).

Cognition: Poor Information Processing. We propose that future certainty during uncertain societal events predicts poor information processing - an ignorance of factual information and adoption of misinformation. When someone is certain (hits the sufficiency threshold), respective information search and processing is felt as unnecessary (e.g., Chaiken et al., 1989; Weary \& Jacobson, 1997). Future certainty, then, should foster ignorance of new information and confirmation bias, and in turn, poor decision making (e.g., Brannon et al., 2007). In contrast, predictions about the future held with doubt (i.e., beliefs; Blumenthal-Barby \& Ubel, 2018) may distance individuals from the sufficiency threshold, and in turn, foster information seeking and well-informed decisions (Dieterich et al., 2016).

Our hypothesis is also supported by recent work on vulnerability to misinformation. Pennycook and Rand (2019) found that a construct thematically related to future certainty, overclaiming (claiming to know more than one can possibly know), predicts greater susceptibility to fake news. They suggest that overclaiming is an index of "non-reflectiveness" (i.e., lower analytical thinking), and therefore, relates to a tendency to fall for highly repeated (and thus fluent) information and a lower tendency to fact-check (Pennycook \& Rand, 2021). Relatedly, recent work by Salovich et al. (2021) found that overconfidence in one's claims 
reduces one's ability to differentiate accurate from inaccurate information during a reading task, suggesting poor information processing.

Despite being theoretically related to overclaiming and overconfidence, future certainty pertains specifically to certainty about something that is in the future-something that is yet unknowable (Gollwitzer \& Oettingen, 2019). Therefore, it should be especially relevant and related to poor information processing in novel or uncertain contexts. During the COVID-19 pandemic, those who held future certainty may have ignored reliable sources and instead embraced conspiratorial thoughts, thereby staying uninformed at a critical time. Or, during a moment of political uncertainty, such as the 2020 Presidential Election, individuals who were certain of the outcome of the election before the election may have ignored facts disconfirming the outcome they predicted, and have been susceptible to unfounded claims (e.g., the election's being rigged). In sum, future certainty during societal events of uncertainty may contribute to poor information processing and in turn intellectual blindness at a particularly inopportune time.

Behavior: Antisocial Responding. We also propose that future certainty during uncertain events may heighten antisocial behavior - acting in ways that harm or endanger others. Certainty entails an experience of possession of knowledge (Abelson, 1986), and thus may be subject to greater loss aversion than holding beliefs with doubt (Tversky \& Kahneman, 1974). Indeed, previous work has found that opposition to attitudes held with certainty (vs. uncertainty) results in antisocial responding in the form of greater competitiveness (Rios et al., 2014) and anger (Niedbala et al., 2018). Relevantly, Mitzen and Schweller (2011) theorize that political conflicts are motivated by misplaced certainty rather than uncertainty. In short, previous work has established certainty as a potential catalyzer of antisocial responding. 
More directly supporting our hypothesis, recent research by Gollwitzer et al. (2021) examined an epistemic structure termed "discordant knowing"-holding high (vs. low) certainty about a personal or societal issue that the majority of others judge as unknowable or wrong. They showed that this epistemic structure contributes to antisocial responding in the form of fanaticism (i.e., heightened aggression, determined ignorance, and an urge to join like-minded groups). Future certainty during uncertain societal events, such as the COVID-19 pandemic, may mirror discordant knowing as the future is unknowable in such contexts, and thus, may lead to the noted antisocial behaviors.

To summarize, past research suggests that future certainty during periods of societal uncertainty may encourage antisocial responding. For instance, during the COVID-19 pandemic, future certainty may have led individuals to ignore preventative COVID-19 measures (e.g., social distancing), in turn infecting vulnerable others. Similarly, regarding the 2020 Presidential Election, future certainty about one's preferred candidate's victory may have encouraged individuals to claim the election was rigged and endorse violence if the preferred candidate lost.

\section{The Present Research}

The COVID-19 pandemic and the 2020 U.S. presidential election-both highly uncertain societal events - provided us with a unique circumstances to begin to examine the psychological outcomes of future certainty during uncertain societal events. Three studies examined whether certainty about the future of the COVID-19 pandemic (Studies 1 and 2) and the 2020 U.S. presidential election (Study 3) predicts cognitive and behavioral outcomes in terms of 1) poor information processing (Studies 1-3), and 2) greater antisocial responding (Studies 2 and 3). Importantly, we always controlled for individuals' matched beliefs about the future (predictions held with some doubt) to delineate the psychological outcomes specific to future certainty. 
Additionally, we examined whether potential outcomes of future certainty remain consistent across predictions of positive (e.g., "I know COVID-19 will disappear soon") and negative futures (e.g., "I know that nothing is going to get better soon").

\section{Study 1: Future Certainty and Poor Information Processing During COVID-19}

Study 1 examined whether certainty about positive or negative COVID-19 futures predicted poor information processing during the pandemic. Poor information processing was assessed via 1) failing to adhere to medical experts, 2) adopting COVID-19 conspiracy theories, and 3) poor objective knowledgeability (performance on a COVID-19 knowledge quiz). To differentiate certainty from beliefs about the future, we measured beliefs about the future independently via content-matched items.

\section{Method}

\section{Participants}

An apriori power analysis for a correlational study with .90 power, an alpha of .05 , and a small effect size $(r=.20)$ suggested that we should recruit 258 participants. Accounting for potential attention check failures and attrition, we requested 300 people on Prolific early in the pandemic (April 2, 2020). Two hundred ninety-six participants (155 females, 137 males, 4 other; $\left.M_{\text {age }}=32.10, S D_{\text {age }}=11.48\right)$ passed the attention check question and remained for analyses. Participants also completed the same measures one and two weeks after the initial assessment. Because the main variables showed strong over-time consistency (see Table S1\&S2 in Supplementary Material A), we only focused on the initial assessment.

\section{Measures}

All measures are available here. 
Future Certainty. Two measures assessed participants' certainty about possible positive and negative COVID-19 futures. A four-item measure assessed certainty about positive COVID19 futures - these items included the term know to capture participants' certainty (e.g., "I know that everything is going to be fine soon"; 1: Strongly Disagree, 7: Strongly Agree; $\omega_{t}=.87$ ) (see Replication Study in Supplemantary Material B). Certainty about a negative COVID-19 future was measured using an analogous 4-item measure (e.g., "I know that nothing is going to get better soon"; $\left.\omega_{t}=.81\right)$.

Beliefs About the Future. Participants also rated matched belief versions of the certainty measures. The measures were identical except the word "know" was replaced with "believe" (e.g., "I believe that everything is going to be fine soon", "I believe that nothing is going to get better soon"; positive: $\omega_{t}=.79$; negative: $\left.\omega_{t}=.75\right)$. This procedure was adapted from past work by Gollwitzer and Oettingen (2019), which has validated the efficacy of measuring certainty versus believing using the terms "know" versus "believe." The order of the certainty and believing measures and the order of items within each measure were randomized.

Cognition: Poor Information Processing. Poor information processing was assessed in three ways: avoiding reliable information sources on COVID-19, seeking unreliable information sources on COVID-19 (i.e., conspiracy theories), and reduced objective knowledgeability about COVID-19. By measuring information processing from reliable and unreliable sources (conspiracy theories) independently, we could examine whether future certainty predicts overall ignorance (i.e., ignorance of the event altogether regardless of the source) or specifically, ignorance of factual information (e.g., expert information). Finally, we assessed how much participants thought they knew about the virus - their subjective COVID-19 knowledgeabilityto compare these judgments to their objective knowledgeability about the virus. 
Reliable Sources. Participants reported the degree to which they adhered to reliable information sources, namely, medical experts ("How are the following factors influencing to what extent you are socially distancing yourself from others?: Medical experts' suggestions;" 1: Not at all, 7: Very much). ${ }^{1}$

Unreliable Sources. Adherence to conspiratorial information was measured via a threeitem measure adapted from van Prooijen's (2016) conspiracy belief measure (e.g., "I believe that scientists are pressured to portray COVID-19 differently than is actually the case"; $\omega_{t}=.79$ ).

Objective and Subjective Knowledgeability About COVID-19. We assessed objective knowledgeability about COVID-19 using a six-item quiz. The quiz was designed based on the available scientific information on the symptoms and spread of COVID-19 at the time (e.g., "The virus stays on plastic surfaces for a longer time than cardboard surfaces, true or false?"). Finally, we assessed subjective knowledgeability; participants self-reported the extent they possessed objective knowledge of COVID-19 on a seven-point scale (How knowledgeable are you about the recent outbreak of Covid-19 [Coronavirus] in your country?; 1: Not at all, 7: Extremely).

Demographics. Participants completed questions about demographic information, including an item assessing political orientation (1: Very Conservative, 7: Very Liberal).

\section{Results}

\section{Preliminary Analyses}

Certainty about positive $(M=3.21, S D=1.51)$ and negative futures of COVID-19 $(M=$ $3.15, S D=1.40$ ) were normally distributed (skewness $<.9$ ). Interestingly, although certainty about positive and negative futures were contradictory in valence, they did not negatively relate

\footnotetext{
${ }^{1}$ We measured social distancing via asking the extent to which participants left their house for shopping and paid attention to maintain six feet distance from others. As stay-at-home orders were in place at the time, a ceiling effect emerged (about $50 \%$ of participants selected the highest scale point).
} 
to one another $(r=.009, n s)$. However, and as expected, beliefs about negative $M=3.80, S D=$ $1.35)$ and positive futures $(M=4.14, S D=1.29)$ did exhibit a strong negative relationship $(r=$ $.44, p<.001$ ). This suggests that future certainty (as opposed to beliefs admitting doubt) may simply be for the sake of certainty in and of itself (regardless of content).

Among demographic variables, only political conservatism (positive future: $r=.14, p=$ .017 , negative future: $r=.13, p=.026$ ) significantly correlated with certainty (after accounting for matched beliefs). This finding aligns with previously documented links between conservatism and the need for certainty and security (see Federico \& Malka, 2018; see Table S3 in Supplementary Material A for all correlations).

\section{Future Certainty and Poor Information Processing During COVID-19}

We conducted a series of multiple regressions, each predicting one of the three included poor information processing variables: avoidance of information from reliable sources (medical experts), seeking unreliable sources (conspiratorial thinking), and low objective COVID-19 knowledgeability. We entered certainty about the future and beliefs about the future simultaneously into the regression models as predictors to examine the unique predictive power of each variable on the outcomes of interest (i.e., the prediction of certainty after controlling for relevant beliefs, and vice versa). We conducted models for positive and negative futures separately (see Table 1 and Figure 1 for all analyses).

In the models, certainty about positive $(p=.012)$ and negative COVID-19 futures $(p=$ .046) predicted a reduced tendency to listen to medical experts. Additionally, future certainty about both positive and negative futures predicted a greater tendency to adhere to conspiracy theories on COVID-19 ( $p \mathrm{~s}<.001)$. These results indicate that certainty, whether it relates to positive or negative futures, specifically predicted poor information processing towards medical 
expertise rather than overall ignorance. Finally, regarding objective COVID-19

knowledgeability, those with greater future certainty (of both positive and negative futures)

performed worse on the COVID-19 quiz (positive future: $p=.001$; negative future: $p=.012$ ). To contrast objective with subjective knowledgeability, we created a knowledgeability gap score by z-transforming objective knowledgeability (performance on the COVID-19 quiz) and subjective knowledgeability and subtracting the former from the latter. When doing so, we found that future certainty significantly predicted this knowledgeability gap; that is, the more certain participants were about the uncertain future, the more they thought they were knowledgeable about the virus as compared how much knowledge they in fact had $(p s<.031)$.

A

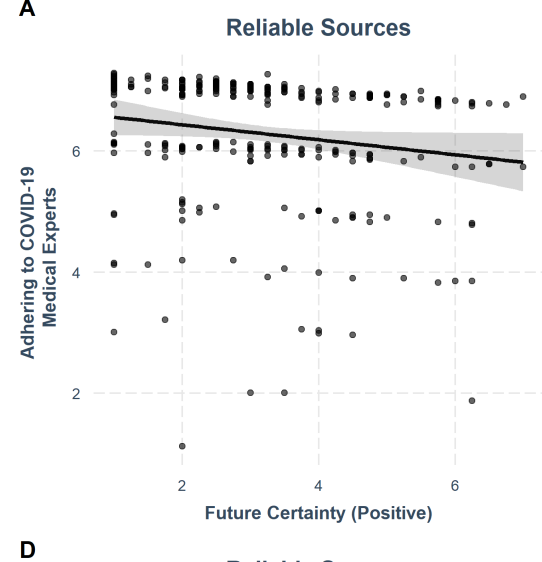

D

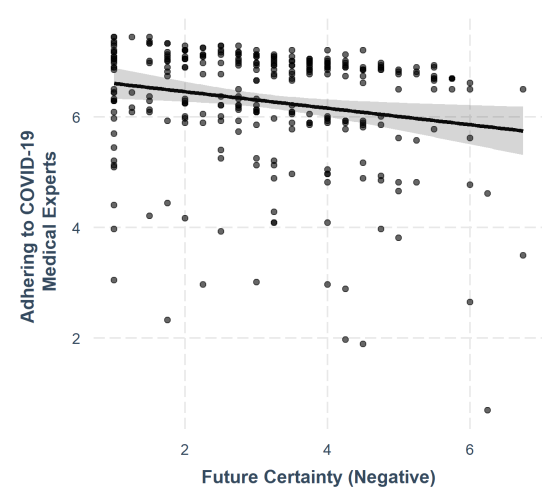

B

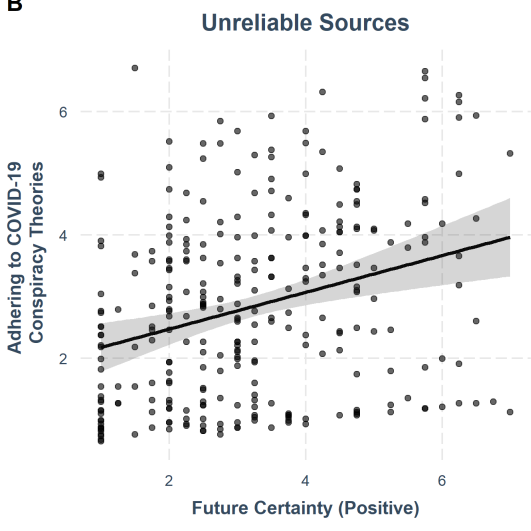

$\mathbf{E}$
C

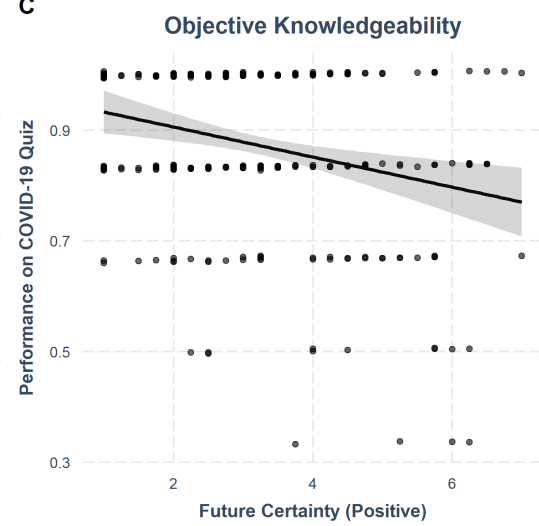

$\mathbf{F}$

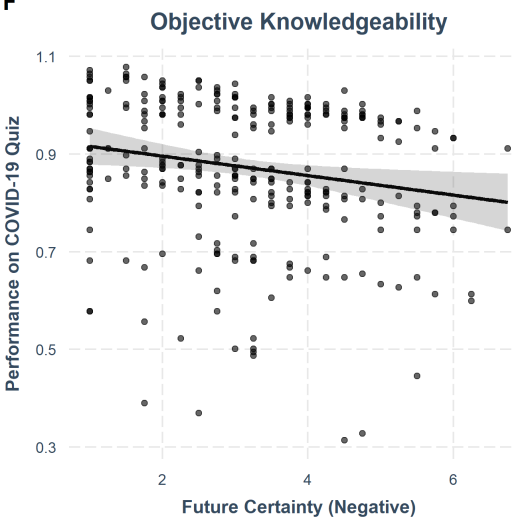

Figure 1. Plots depicting the partial effect of future certainty on poor information processing (Study 1). Plots A-C depict the relationship between certainty about positive COVID-19 futures and $\mathrm{A}$. adhering to medical experts, $\mathrm{B}$. adhering to conspiracy theories and $\mathrm{C}$. performance on a COVID-19 quiz. Plots D-F depict the relationship between certainty about negative COVID-19 
futures and the noted variables. All models account for relevant beliefs about the future. Error bands: 95\% CIs (using geom_ribbon in R).

Beliefs about positive COVID-19 futures did not relate to information processing or objective knowledgeability about COVID-19. Beliefs about negative COVID-19 futures predicted information processing variables, but in the opposite direction to certainty; it predicted a higher tendency to listen to medical experts, a lower tendency to endorse conspiracy theories, higher objective knowledgeability, and a lower knowledgeability gap $(p s<.038)$. These findings are consistent with past work showing that negative affective states facilitate informationprocessing in general (Peeters \& Czapinski, 1990; Kappes, Pak, \& Oettingen, 2012) whereas positive affective states may or may not impact information processing (see Wegener et al., 1995).

Table 1

Study 1. Multiple Regression Analyses

\begin{tabular}{|c|c|c|c|c|c|}
\hline & & $t(d f=293)$ & $\beta$ & $p$ & $95 \%$ CI $\beta$ \\
\hline \multicolumn{2}{|l|}{ Model } & \multicolumn{4}{|c|}{ Seeking Reliable Sources (Medical Experts) } \\
\hline \multirow[t]{2}{*}{ Positive Future } & Certainty & -2.00 & -.17 & .046 & {$[-.34,-.003]$} \\
\hline & Belief & 1.26 & .11 & .208 & {$[-.06, .28]$} \\
\hline \multirow{2}{*}{ Negative Future } & Certainty & -2.53 & -.19 & .012 & {$[-.34,-.04]$} \\
\hline & Belief & 2.58 & .20 & .010 & {$[.05, .34]$} \\
\hline & & \multicolumn{4}{|c|}{ Seeking Unreliable Sources (Conspiratorial Thinking) } \\
\hline \multirow[t]{2}{*}{ Positive Future } & Certainty & 3.63 & .30 & $<.001$ & {$[.14, .47]$} \\
\hline & Belief & -1.17 & -.10 & .242 & {$[-.26, .07]$} \\
\hline \multirow[t]{2}{*}{ Negative Future } & Certainty & 4.51 & .34 & $<.001$ & {$[.19, .48]$} \\
\hline & Belief & -2.10 & -.16 & .037 & {$[-.30,-.01]$} \\
\hline & & \multicolumn{4}{|c|}{ Objective Knowledgeability (COVID-19 Quiz) } \\
\hline \multirow[t]{2}{*}{ Positive Future } & Certainty & -3.38 & -.28 & .001 & {$[-.44,-.12]$} \\
\hline & Belief & -.23 & -.02 & .815 & {$[-.18, .14]$} \\
\hline \multirow[t]{3}{*}{ Negative Future } & Certainty & -2.52 & -.19 & .012 & {$[-.34,-.04]$} \\
\hline & Belief & 3.38 & .25 & .001 & {$[.11, .40]$} \\
\hline & & \multicolumn{4}{|c|}{ Knowledgeability Gap (Subjective - Objective) } \\
\hline \multirow[t]{2}{*}{ Positive Future } & Certainty & 2.19 & .18 & .030 & {$[.02, .34]$} \\
\hline & Belief & 1.47 & .12 & .142 & {$[-.04, .28]$} \\
\hline Negative Future & Certainty & 2.50 & .19 & .013 & {$[.04, .34]$} \\
\hline
\end{tabular}


$\frac{\text { Belief }}{\text { Note. } \beta \text { coefficients are from fully standardized models. }}$

\section{Study 2: Future Certainty and Noncompliance with Preventive COVID-19 Measures}

Study 1 found that future certainty relates to poor information processing within the context of the COVID-19 pandemic. Study 2 focused on the manifestation of poor information processing in behavior: Does certainty about the future relate to lower compliance with preventive health measures? Since such noncompliance behaviors can be considered antisocial, as they increase viral spread resulting in others' hospitalization or death, Study 2 provides initial insight into whether future certainty predicts antisocial behavior during uncertain societal events.

Additionally, in Study 2, we tested the temporal stability of the proposed links. That is, we tested whether future certainty regarding COVID-19 at Time 1 predicts noncompliance with preventive health behaviors assessed approximately one week later (Time 2). To examine the robustness of the hypothesized relationships, we assessed and controlled for participants' tendency to provide socially desirable responses and their general impulsivity; two factors that have been linked to individuals' compliance with preventive health measures previously (e.g., Kristiansen \& Harding, 1984; Thoma et al., 2021).

Notably, Study 2 focused on noncompliance with COVID-19 health behaviors during the 2020 Thanksgiving holiday. We suspected that some people may fail to comply with COVID-19 health guidelines by traveling or inviting guests over the holidays; indeed, the CDC warned that Thanksgiving might be a critical event in terms of viral spread (Forster \& Ranualt, 2020).

\section{Method}

\section{Participants}


Three hundred participants were invited to the study through Prolific two days before Thanksgiving 2020 (Time 1) and again five days after Thanksgiving 2020 (Time 2) (see Study 1 for power analyses). One participant's response was missing due to a technical error. Another participant failed both attention check questions. Analyses were conducted on 298 participants (160 female, 133 male, 5 nonbinary; $\left.M_{\text {age }}=34.86, S D_{\text {age }}=12.44\right)$ at Time 1 . Among these, 245 participants (136 female, 104 male, 5 nonbinary; $\left.M_{\text {age }}=34.49, S D_{\text {age }}=12.69\right)$ answered the follow-up survey (Time 2; one week later).

\section{Time 1 Materials (Before Thanksgiving)}

All measures are available here.

Future Certainty. Participants' certainty about positive $\left(\omega_{t}=.88\right)$ and negative $\left(\omega_{t}=\right.$ .80) COVID-19 futures was assessed via the three items included in Study 1. We removed one item about finding the cure for COVID-19 from the original measure due to the medical developments at the time.

Beliefs About the Future. Belief items were identical to the certainty items, except the word know was replaced with believe (positive: $\omega_{t}=.79$; negative: $\omega_{t}=.69$ ).

Noncompliance with Preventive Health Practices. Failure to follow preventive COVID-19 health practices was assessed in three ways: Recent in-person contact with others, intentions for in-person contact during the Thanksgiving holiday (through inviting guests and traveling), and mask-wearing.

In-Person Contact. Participants reported the number of days in the past week that they had in-person contact with familiar others who are not from their household ( 0 days -7 days).

Intentions for In-Person Contact During Thanksgiving. We included two items. First, we tested participants' intentions of inviting others for Thanksgiving: "Are you planning to 
invite people to your house for Thanksgiving?" (yes/no). Additionally, we tested intentions to travel during the Thanksgiving holiday: "Are you planning to travel (or have you already traveled) for the Thanksgiving holiday?" (yes/no).

Mask-Wearing. Mask-wearing was measured by subtracting the ratings on an item measuring the frequency of mask-wearing during the pandemic ("After the COVID-19 pandemic has started, you [insert the frequency of choice] wear a mask when you go outside," 1 : Never, 7: Always) from the frequency of mask-wearing before the pandemic ("Before the COVID-19 pandemic, you [insert the frequency of choice] wore a mask when you went outside," 1: Never, 7: Always).

Social Desirability. To account for participants providing socially desirable responses to questions about their preventive health practices, we assessed social desirability via a 13-item version of the Marlowe-Crowne Social Desirability Scale (Reynolds, 1982), $\omega_{t}=.74$.

Intuitive Thinking. To control for potential intuitive thinking effects (see Thoma et al., 2021), we measured analytical (vs. intuitive) thinking through the 3-item Cognitive Reflection Test (CRT). Higher CRT scores (calculated by taking the average of three questions) indicate greater analytical (vs. intuitive) thinking, $\omega_{t}=.74$.

Demographics. The demographic measures were as in Study 1.

\section{Time 2 Materials (After Thanksgiving).}

About one week after Time 1, participants responded to questions about in-person contact in the past seven days (capturing the Thanksgiving holiday) and traveling and inviting guests for Thanksgiving (they responded to the same questions in terms of their performed behaviors instead of intentions). We also measured mask-wearing among those who traveled or invited guests during the holiday. Because of the comparatively small number of participants who 
reported traveling or inviting guests, we did not have sufficient statistical power to test maskwearing at Time 2 .

\section{Results}

\section{Preliminary Analyses}

Consistent with Study 1, certainty about positive COVID-19 futures $(M=2.96, S D=$ 1.66) did not negatively predict certainty about negative COVID-19 futures $(M=3.05, S D=$ 1.53) despite the contradictory valence; on the contrary, we observed a small positive correlation between these two variables, $r(298)=.12, p=.03$. Beliefs again differed from certainty; beliefs about positive COVID-19 futures $(M=3.85, S D=1.45)$ negatively related to beliefs about negative COVID-19 futures $(M=3.62, S D=1.40), r(298)=-.43, p<.001$. As in Study 1 , future certainty related to political conservatism after accounting for beliefs about the future, (positive future: $r=.23, p<.001$, negative future: $r=.27, p<.001$; see Table S3).

\section{Future Certainty and Lack of Preventive Health Practices}

Time 1 (Before Thanksgiving). We applied the same regression analyses as in Study 1, but onto preventative COVID-19 behaviors (see Table 2 and Figure 2). After accounting for beliefs about the future, both certainty about positive and negative COVID-19 futures predicted more days with in-person contact with familiar others (i.e., lower social distancing; $p=.017$ and $p=.004$, respectively). Both forms of certainty also positively predicted participants' intentions to invite guests (or having already invited guests; $\mathrm{N}=47$ ) to their homes for Thanksgiving despite rising COVID-19 infection rates $(p s<.007)$. Future certainty did not relate to traveling plans ( $p$ s > .6; see Table S4 in Supplementary Material A), however, perhaps because the ability to travel depended on the state guidelines at the time (twelve states had active travel restrictions; Wonacott, 2020). Also, notably, a smaller number of participants reported having travel plans (n 
=33). Finally, while certainty about positive COVID-19 futures predicted reduced maskwearing, $p=.004$, certainty about negative COVID-19 futures did not convincingly predict reduced mask-wearing (only a marginal link was observed, $p=.060$; see Table 2).

Time 2 (Follow-up After Thanksgiving). The patterns were largely consistent in the follow-up survey after Thanksgiving (Time 2; 7 days after Time 1). Both types of future certainty predicted having had guests over for Thanksgiving $(n=41 ; p s<.018)$. Additionally, both types of future certainty predicted more days of in-person contact with familiar others during that timeframe (in the prior week, which included the Thanksgiving holiday; $p \mathrm{~s}<.022$ ). Future certainty again did not relate to traveling plans $(n=31 ; p s>.1)$.

\section{Beliefs About the Future and Preventive Health Practices}

As in Study 1, beliefs about the future differed from future certainty. Beliefs about negative COVID-19 futures significantly predicted not having guests over for Thanksgiving (Time $2, p=.006$ ) and marginally predicted lower in-person contact with others before and during Thanksgiving $(p s<.085)$. Beliefs about positive COVID-19 futures did not relate significantly to preventive practices $(p \mathrm{~s}>.286)$.

\section{Robustness Checks}

As robustness checks, we reconducted the analyses predicting noncompliance with COVID-19 health behaviors when including intuitive thinking (i.e., CRT scores) or social desirability as additional predictors. When doing so, the pattern of results remained the same across all preventative behaviors (see Table S5-S6 in Supplementary Material A). 
A

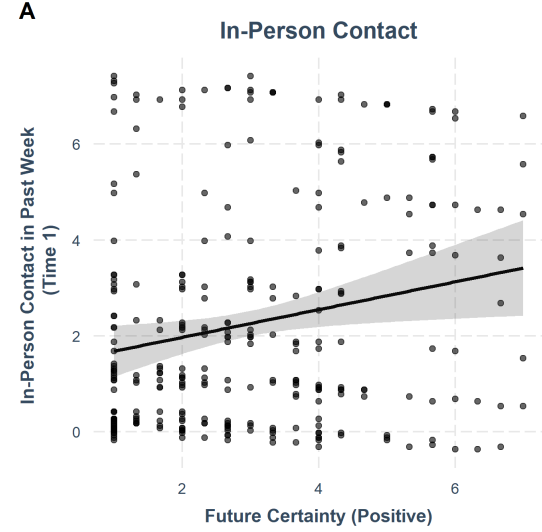

D

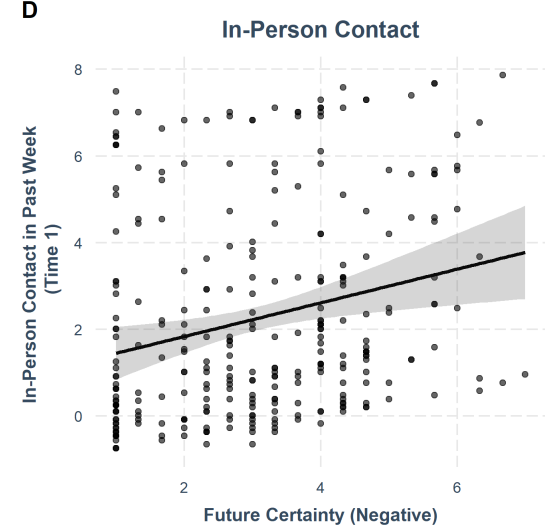

B

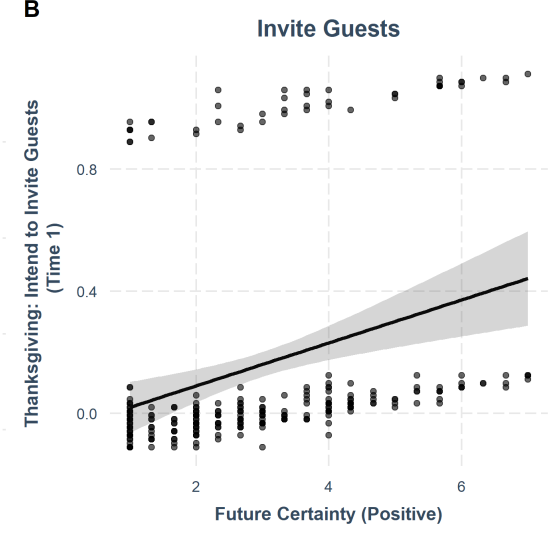

E

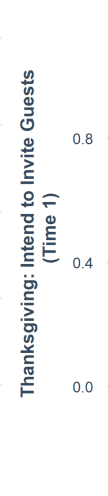

c

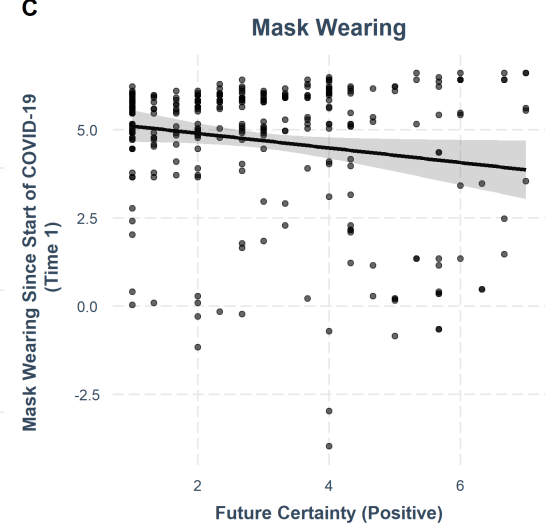

F

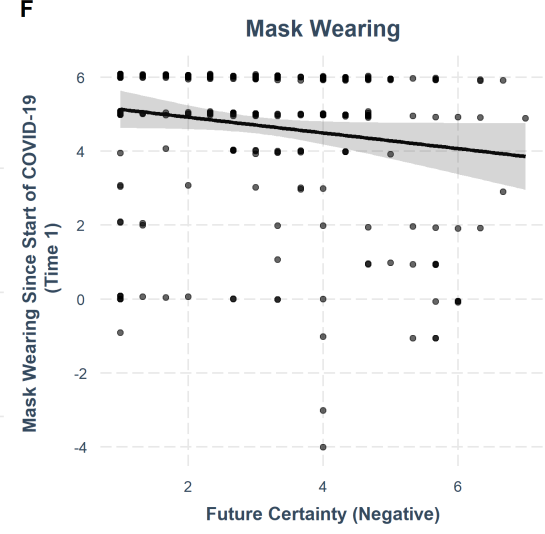

Figure 2. Plots depicting the partial effect of future certainty on noncompliance with health practices (Study 2). Plots A-C depict the relationship between certainty about positive COVID19 futures and A. in-person contact in the past week, B. plans for inviting guests for Thanksgiving, and C. mask-wearing. Plots D-F depict the relationship between certainty about negative COVID-19 futures and the noted practices. All models account for relevant beliefs about the future. Error bands: 95\% CIs (using geom_ribbon in R).

\section{Table 2}

Study 2. Multiple Regression Analyses

\begin{tabular}{|c|c|c|c|c|c|c|c|c|c|}
\hline & & \multicolumn{4}{|c|}{ Time 1} & \multicolumn{4}{|c|}{ Time 2} \\
\hline & & $t(d f=295$ & $\beta$ & $p$ & $95 \% \mathrm{CI} \beta$ & $t(d f=241)$ & $\beta$ & $p$ & $95 \%$ CI $\beta$ \\
\hline \multicolumn{2}{|c|}{ Model } & \multicolumn{4}{|c|}{$\begin{array}{l}\text { In-Person Contact w/ Familiar Others } \\
\text { (Before the Thanksgiving Holiday) } \\
\qquad M=2.25, S D=2.37\end{array}$} & \multicolumn{4}{|c|}{$\begin{array}{c}\text { In-Person Contact w/ Familiar Others } \\
\text { (During the Thanksgiving Holiday) } \\
\qquad M=2.18, S D=2.26\end{array}$} \\
\hline \multirow[t]{2}{*}{ Positive Future } & Certainty & 2.40 & .20 & .017 & {$[.04, .37]$} & 2.32 & .22 & .021 & {$[.03, .42]$} \\
\hline & Belief & 1.07 & .09 & .287 & {$[-11,11]$} & -.45 & -.04 & .656 & {$[-.22, .14]$} \\
\hline \multirow[t]{2}{*}{ Negative Future } & Certainty & 2.90 & .25 & .004 & {$[.08, .42]$} & 2.71 & .24 & .007 & {$[.07, .44]$} \\
\hline & Belief & -1.94 & -.17 & .053 & {$[-.34, .002]$} & -1.74 & -.16 & .084 & {$[-.35, .02]$} \\
\hline
\end{tabular}




\begin{tabular}{|c|c|c|c|c|c|c|c|c|c|}
\hline \multirow{3}{*}{ Positive Future } & \multirow{3}{*}{$\begin{array}{l}\text { Certainty } \\
\text { Belief }\end{array}$} & \multicolumn{4}{|c|}{$\begin{array}{c}\text { Intention to Invite Guests for } \\
\text { Thanksgiving } \\
\mathrm{n}_{\mathrm{yes}}=47 ; \mathrm{n}_{\mathrm{no}}=251\end{array}$} & \multicolumn{4}{|c|}{$\begin{array}{l}\text { Having Guests Over for Thanksgiving } \\
\qquad \mathrm{n}_{\mathrm{yes}}=41 ; \mathrm{n}_{\mathrm{no}}=203\end{array}$} \\
\hline & & 3.74 & .32 & $<.001$ & {$[.15, .49]$} & 2.39 & .22 & .017 & {$[.04, .43]$} \\
\hline & & -1.82 & -.16 & .070 & {$[-.31, .01]$} & -1.35 & -.12 & .177 & {$[-.31, .06]$} \\
\hline \multirow[t]{3}{*}{ Negative Future } & Certainty & 2.78 & .24 & .006 & {$[.07, .41]$} & 3.14 & .29 & .002 & {$[.11, .49]$} \\
\hline & Belief & -1.68 & -.15 & .093 & {$[-.32, .02]$} & -2.74 & -.25 & .006 & {$[-.45,-.08]$} \\
\hline & & \multicolumn{8}{|c|}{$\begin{array}{c}\text { Mask-Wearing (General) } \\
M=4.70, S D=1.99\end{array}$} \\
\hline \multirow[t]{2}{*}{ Positive Future } & Certainty & -2.06 & -.17 & .041 & {$[-.34,-.01]$} & - & & - & - \\
\hline & Belief & -1.66 & -.14 & .097 & {$[-.30, .03]$} & - & & - & - \\
\hline \multirow[t]{2}{*}{ Negative Future } & Certainty & -1.89 & -.16 & .060 & {$[-.33, .01]$} & - & & - & - \\
\hline & Belief & .27 & .02 & .787 & {$[-.15, .19]$} & - & & - & - \\
\hline
\end{tabular}

Note. $\beta$ coefficients are for fully standardized models. Left panel shows predictions for outcomes measured at Time 1 and right panel shows predictions for outcomes measured at Time 2 .

\section{Study 3: Future Certainty and the 2020 Presidential Election}

Study 3 had two main goals. First, we examined whether future certainty is linked to poor information processing during another important societal event of uncertainty: the 2020 U.S. Presidential Election. Poor information processing was assessed via participants’ endorsement of the 2020 Election as rigged or fraudulent. Indeed, past work has used the claim of rigged elections to measure conspiratorial thinking (e.g., Lamberty et al., 2018), and thus, poor information processing (see Van Proiijen et al., 2015). Second, we more directly examined whether future certainty (during uncertain events) is linked to antisocial responding. To do so, we tested whether future certainty that one's preferred candidate would win the 2020 Election predicted greater endorsement of violence as an acceptable behavior if that candidate lost and, in the case of Trump supporters, the degree to which they identified with the insurrectionists who violently stormed the United States Capitol on January $6^{\text {th }}, 2021 .^{2,3}$

\footnotetext{
${ }^{2}$ Given that political conservatives report higher future certainty (Study $1 \& 2$ ) as well as conspiratorial thinking (e.g., Lamberty et al., 2018), we also tested whether these links were stronger for Trump supporters when the outcome was not clear.

${ }^{3}$ As the January $6^{\text {th }}, 2021$ insurrection was unexpected, these analyses were exploratory.
} 
In addition to these two goals, Study 3 considered what happens when one's future certainty is confirmed versus disconfirmed. Predictions about the future usually have some endpoint, at which reality either confirms or disconfirms one's prediction. The 2020 Presidential Election provided an ideal test case to examine such confirmation versus disconfirmation. That is, the election allowed us to examine whether future certainty is linked to poor information processing and antisocial behavior under three different possibilities: 1) the election results were not yet clear-predictions about the future were neither confirmed nor disconfirmed (Time 1: the day before the election; Time 2: the day after the election), 2) the election results were clear and confirmed participants' predictions (Time 3: a day after the inauguration), and 3) the election results were clear and disconfirmed participants' predictions (Time 3: a day after the inauguration).

Specifically, we hypothesized that, consistent with Studies 1 and 2, future certainty about the outcome of the election prior to confirmation or disconfirmation (Time 1 and 2) should predict poor information processing (claiming that the election would be rigged) and antisocial behavior (endorsing violence as acceptable if one's candidate lost). Additionally, we hypothesized that future certainty about the election outcome would still predict poor information processing and antisocial behavior if participants' predictions were disconfirmed (if their preferred candidate lost the election; Time 3). On the other hand, if participants' predictions were ultimately confirmed (their preferred candidate won; Time 3), these hypothesized links with poor information processing and antisocial behavior should be eliminated.

\section{Method}

\section{Participants}


One thousand participants were invited to the study through Prolific. We oversampled (see previous studies for power analyses) to reach a substantial number of Trump and Biden supporters. Three participants submitted the study with no completion code and data. One participant completed the study twice, and their second submission was removed. Twenty-one participants failed the attention check. We retained 975 participants (540 female, 403 male, 31 nonbinary, one missing; $M_{\text {age }}=32.21, S D_{\text {age }}=11.35$ ) at Time 1 of the study. Participants who did not vote or were not eligible to vote or voted for candidates other than Trump and Biden were excluded from the analyses. A total of 624 participants remained at Time 2 (111 Trump, 513 Biden supporters), and 427 participants remained at Time 3 (69 Trump, 358 Biden supporters). See Table S7 in Supplementary Material A for distributions. See pre-registration $\underline{\text { here. }}$

\section{Materials}

Certainty about the election results was assessed at Time 1 (the day before the election), as was participants' endorsement of antisocial behavior (violence if one's preferred candidate might lose). At Time 2 (one day after the election), we assessed poor information processing (claiming the election was rigged) and re-assessed antisocial behavior. At Time 3 (one day after the inauguration), we again assessed poor information processing and antisocial behavior; however, antisocial behavior was assessed via participants' identification with the January $6^{\text {th }}$ capitol insurrectionists. Other exploratory variables were measured as described below.

\section{Time 1 Materials (The Day Before the Election).}

Preferred Candidate. Participants selected the candidate they planned to vote for (or had voted for earlier via mail) in the upcoming election. The options also included not voting or not being eligible to vote. 
Future Certainty About the Outcome of the Election. Participants rated the statement "I know and am certain that [the preferred candidate's name piped in here] will be elected as the next president" (1: Strongly disagree, 7. Strongly agree). We explicitly included the term "certainty" in the item to ensure that our findings extend beyond the operationalization of certainty versus belief utilized in Studies 1 and 2 (solely varying the terms "know" and "believe").

Beliefs About the Outcome of the Election. Participants rated the statement, "I believe but have doubts that [the preferred candidate's name piped in here] will be elected as the next president (1: Strongly disagree, 7. Strongly agree). Again, we explicitly included the term "doubts" in the item to ensure that our findings extend beyond the operationalization of certainty versus belief utilized in Studies 1 and 2 (solely varying the terms "know" and "believe").

Antisocial Tendencies: Endorsing Violence. We assessed the degree to which participants endorsed violent tendencies if their predicted future - that their preferred candidate would be elected — did not occur ("How strongly do you agree with the following statement?: Violence would be justified if [the preferred candidate's name piped in here] loses the upcoming presidential election; 1. Strongly disagree, 7. Strongly agree).

Candidate Support. To explore whether future certainty about the outcome of the election predicts the assessed outcome variables above and beyond the strength of support for one's candidate, we measured participants' support for their preferred candidate ('How strongly do you support your candidate?; 1: Moderately strong, 7: Extremely strong).

Time 2 Materials (The Day After the Election).

Poor Information Processing: Rigged Election Claims. After participants selected their preferred candidate, they reported whether the election had been rigged by evaluating the item: 
“The 2020 Presidential Election was rigged" on a 7-point scale (1: No, not at all true, 7: Yes, absolutely true). ${ }^{4}$

Antisocial Responding: Endorsing Violence. Same measure as Time 1.

Time 3 Materials (The Day After the Inauguration).

Poor Information Processing: Rigged Election Claims. Same measure as Time 2.

Antisocial Responding: Identifying with the Capitol Insurrectionists. We replaced the endorsing violence measure with a three-item scale measuring the extent to which participants identified with the Capitol insurrectionists (e.g., "Those who stormed the Capitol are not different from people like me," 1: Strongly disagree, 7. Strongly agree), $\omega_{t}=.81$.

\section{Results}

\section{Preliminary Analyses}

We first compared Trump and Biden supporters in terms of their future certainty and beliefs about the future. Trump supporters were significantly more likely $(M=4.33, S D=1.74)$ than Biden supporters $(M=3.68, S D=1.46)$ to exhibit future certainty that their candidate would win the election, $t(145.64)=3.61, p<.001$. At the same time, Biden supporters $(M=5.1, S D=$ 1.47) were significantly more likely than Trump supporters $(M=4.51, S D=1.82)$ to believe (less certainty) that their candidate would win, $t(145.76)=-3.73, p=.002$. These findings align with the observed link between future certainty and political conservatism in Studies 1 and 2.

\section{Main Analyses}

\footnotetext{
${ }^{4}$ As a secondary measure, participants also selected who they thought the true winner of the election was (Trump or Biden). Findings regarding the presumed true winner were consistent with findings on rigged election claims, as Trump supporters who claimed that the election was rigged mostly selected Trump as the true winner. See Supplementary Material A for these analyses.
} 
We applied the same regression analyses as in Studies 1 and 2; we entered future certainty and beliefs about the future (that one's candidate would win the election) as predictors and poor information processing and antisocial responding as the outcome variables. ${ }^{5}$ The specific outcome variables are discussed below. All analyses were conducted separately for Trump and Biden supporters (as pre-registered).

\section{Poor Information Processing.}

Before the Outcome was Official (The Day After the Election, Time 2). As predicted, future certainty that one's preferred candidate would win the election, assessed at Time 1, predicted poor information processing, that is, greater endorsement of the election as having been rigged at Time 2 (when the election results were not yet finalized; see Table 3 and Figure 3). This relationship was significant for both Trump $(\beta=.27, p=.004)$ and Biden supporters $(\beta=$ $.10, p=.02)$. The strengths of the observed links did not significantly differ between Trump and Biden supporters (the estimated 95\% confidence intervals overlapped, $p>.05$ ).

After the Outcome was Official (The Day After the Inauguration, Time 3). After the election was officially called for Biden (Time 3), future certainty that Trump would win the election (assessed at Time 1), predicted poor information processing-claiming that the election was rigged $(\beta=.46, p<.001)$. Among Biden supporters, and indicating that confirmation of one's prediction about the future eliminates the noted outcomes of future certainty, future certainty no longer predicted that the election was rigged $(\beta=-.03, p=.522)$.

Finally, unlike future certainty, believing that one's candidate (Trump or Biden) would win the election (i.e., holding some doubt) did not predict poor information processing at any

\footnotetext{
${ }^{5}$ We preregistered to conduct hierarchical regression analyses entering demographic variables at Step 1, believing that one's preferred candidate would win at Step 2, and future certainty at Step 3 as predictors. Controlling for demographic variables did not impact any findings (see Table S8-S10 in Supplementary Material A). To be consistent with previous studies, we decided to report multiple regressions with only certainty and beliefs here.
} 
time point (T2 or $\mathrm{T} 3 ; p \mathrm{~s}>.17)$. These results aligned with our pre-registered hypotheses.

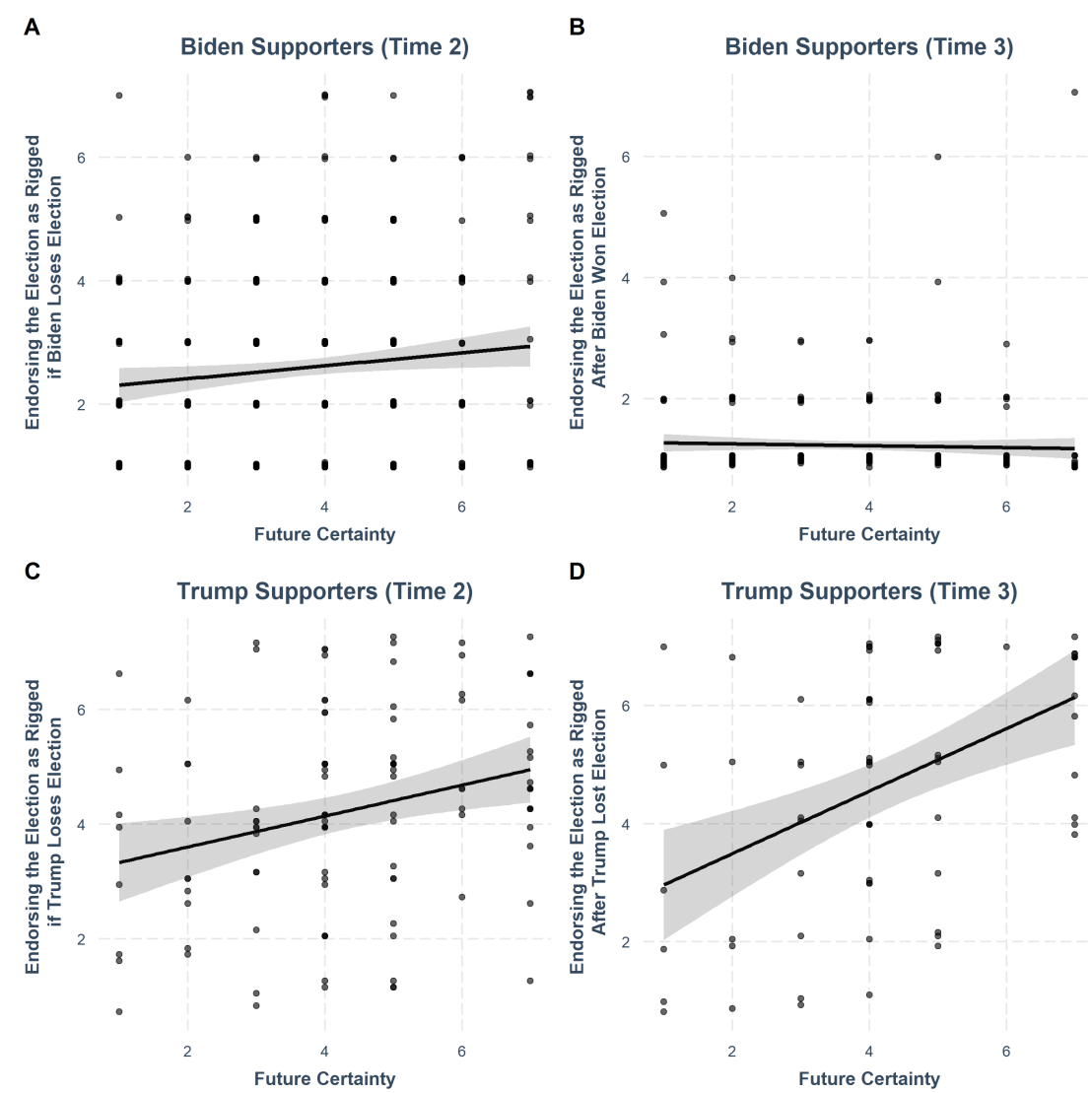

Figure 3. Plots depicting the partial effect of future certainty about the election results on rigged election claims (Study 3). Plots A-B depict the relationship between future certainty among Biden supporters and rigged election claims A. before the election outcome was official (Time 2). and B. after the outcome was official (Time 3). Plots C-D depict the relationship between future certainty among the Trump supporters and rigged election claims during the noted periods. All models account for relevant beliefs about the future. Error bands: 95\% CIs (using geom_ribbon in R).

\section{Antisocial Responding.}

\section{Before the Outcome was Official (The Day Before and The Day After the Election;}

Time $1 \&$ Time 2). At Time 1 (the day before the election), future certainty that one's preferred candidate would win the election predicted greater antisocial tendencies, that is, greater endorsement of violence at Time 1 as an acceptable response if one's preferred candidate 
(hypothetically) lost the election (Trump supporters: $\beta=.40, p<.001$; Biden supporters: $\beta=.11$, $p=.011 ;$ see Table 3 and Figure 4).

Certainty that one's preferred candidate would win at Time 1 also predicted greater endorsement of violence at Time 2 (when the election results were still inconclusive) among Trump supporters $(\beta=.28, p=.003)$. This relationship did not reach statistical significance among Biden supporters $(\beta=.07, p=.092) .{ }^{6}$ Still, the strength of the link between certainty and endorsement of violence did not statistically differ across Trump and Biden supporters as the estimated 95\% confidence intervals (via bias-corrected bootstrap with 1000 samples) revealed overlapping CIs $(p>.05)$. Finally, believing one's preferred candidate would win again showed different patterns of results. Believing that Trump would win marginally related to endorsing violence at Time $1(\beta=.16, p=.059)$ but it was not related to endorsing violence at Time $2(\beta=$ $.03, p=.740)$. Believing that Biden would win the election did not predict endorsing violence at either time point (Time 1 or Time $2 ; p s>.43$ ).

After the Outcome was Official (The Day after the Inauguration, Time 3). We next examined whether future certainty that Trump would win the election (before the election; Time 1) predicted identifying with the Capitol insurrectionists at Time 3 (as a proxy indicator of endorsing violence). Analyses confirmed this to be the case $(\beta=.391, p<.001)$. Unlike future certainty, believing that Trump would win the election (at Time 1) did not predict identifying with the Capital insurrectionists $(\beta=-.02, p=.84)$. Finally, future certainty and beliefs that

\footnotetext{
${ }^{6}$ This may be due to the election results leaning towards Biden the day after the election. Additionally, the relationship between certainty and violent tendencies at Time 2 was also statistically significant among Biden supporters when demographics variables were controlled (see Table S8 in Supplementary Material A).
} 
Biden would win the election did not predict identifying with the Capital insurrectionists

(certainty: $\beta=.09, p=.08$; beliefs: $\beta=-.08, p=.15){ }^{7}$

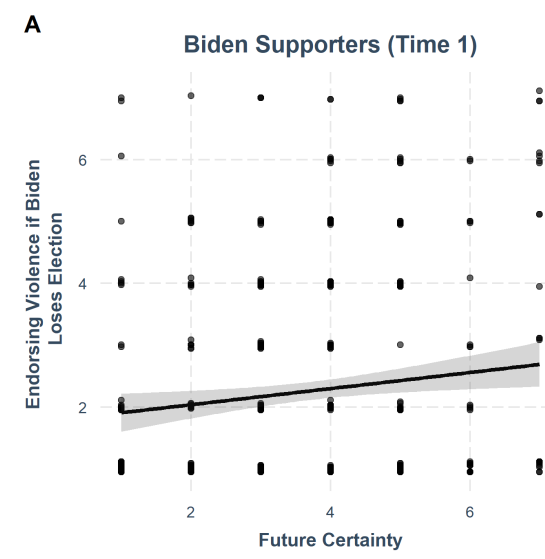

D

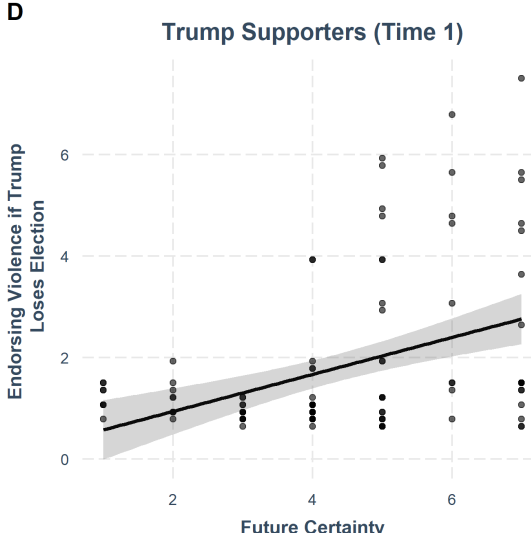

B

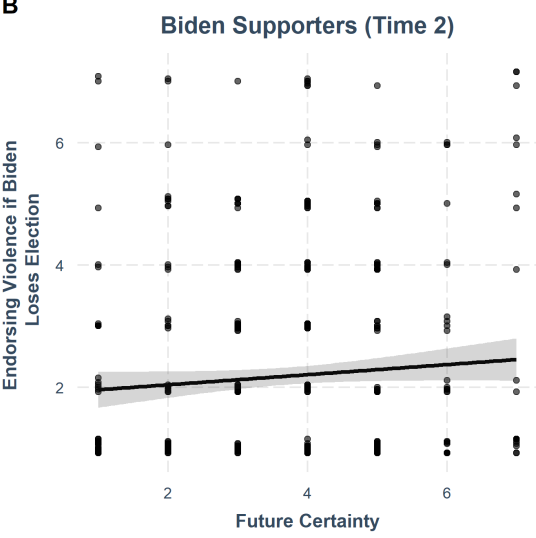

E

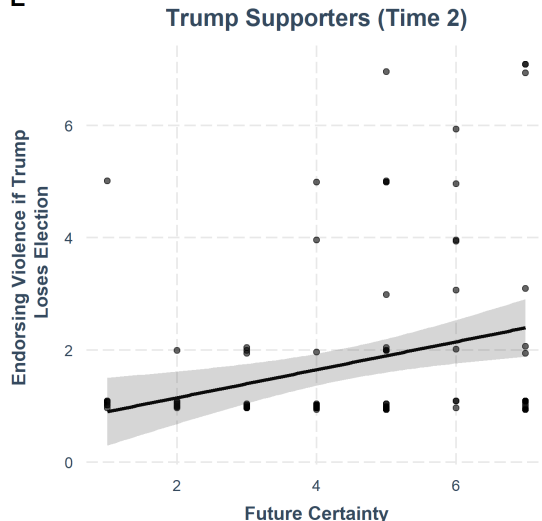

C

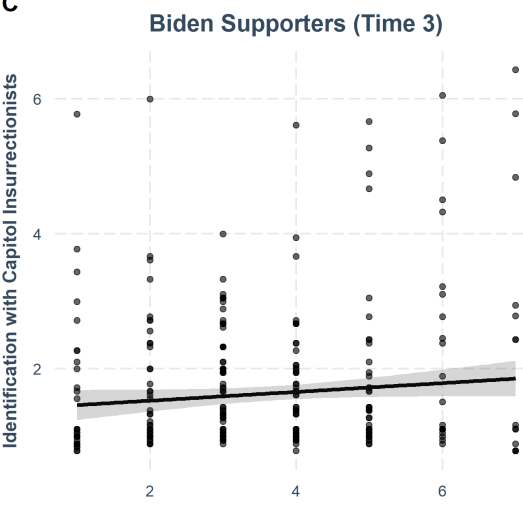

Future Certainty

Trump Supporters (Time 3)

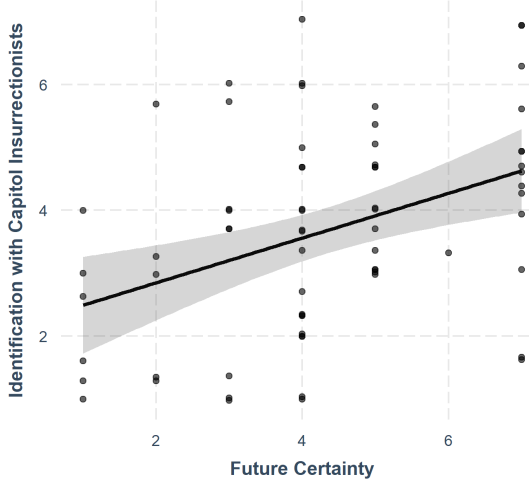

Figure 4. Plots depicting the partial effect of future certainty about the election results on endorsing violence (Study 3). Plots A-C depict the relationship between future certainty among Biden supporters and endorsing violence A. before the election (Time 1), B. before the election outcome was official (Time 2). and C. after the outcome was official (Time 3). Plots D-F depict the relationship between future certainty among the Trump supporters and endorsing violence during the noted periods. All models account for relevant beliefs about the future. Error bands: 95\% CIs (using geom_ribbon in R).

\section{Table 3}

Study 3. Multiple Regression Analyses

\section{TRUMP SUPPORTERS}

\section{BIDEN SUPPORTERS}

\footnotetext{
${ }^{7}$ We also explored whether future certainty predicted identifying with the Capitol insurrectionists after accounting for violent tendencies reported at Time 1 in a multiple regression analysis. Remarkably, certainty that Trump would win the election (at Time 1) was a significant predictor $(\beta=.32, p=.010)$ even after accounting for participants' pre-existing violent tendencies, showing the robustness of the observed links.
} 


\begin{tabular}{lccccc|ccccc}
\hline & $t$ & $d f$ & $\beta$ & $p$ & $95 \%$ CI $\beta$ & $t$ & $d f$ & $\beta$ & $p$ & $95 \%$ CI $\beta$ \\
\hline \multicolumn{7}{c}{ Endorsing the Election as Rigged at Time 2 (Before the Outcome was Official) } \\
\hline Certainty & 2.95 & 108 & .27 & .004 & {$[.09, .45]$} & 2.29 & 510 & .10 & .022 & {$[.01, .18]$} \\
Belief & -1.24 & 108 & -.11 & .219 & {$[-.30, .07]$} & .28 & 510 & .01 & .777 & {$[-.07, .10]$} \\
\hline \multicolumn{8}{c}{ Endorsing the Election as Rigged at Time 3 (After the Outcome was Official) } \\
\hline Certainty & 4.25 & 66 & .46 & $<.001$ & {$[.24, .66]$} & -.64 & 355 & -.03 & .522 & {$[-.14, .07]$} \\
Belief & -.48 & 66 & -.05 & .633 & {$[-.26, .16]$} & -1.35 & 355 & -.07 & .180 & {$[-.18, .03]$} \\
\hline \multicolumn{8}{c}{ Endorsing Violence at Time 1 (Before the Election) } \\
\hline Certainty & 4.63 & 108 & .40 & $<.001$ & {$[.23, .57]$} & 2.56 & 510 & .11 & .011 & {$[.03, .20]$} \\
Belief & 1.91 & 108 & .16 & .059 & {$[-.01, .34]$} & .54 & 510 & .02 & .587 & {$[-.06, .11]$} \\
\hline \multicolumn{8}{c}{ Endorsing Violence at Time 2 (Before the Outcome was Official) } \\
\hline Certainty & 3.07 & 108 & .28 & .003 & {$[.10, .47]$} & 1.69 & 510 & .07 & .092 & {$[-.01, .16]$} \\
Belief & .33 & 108 & .03 & .740 & {$[-.15, .21]$} & .78 & 510 & .03 & .435 & {$[-.05, .12]$} \\
\hline \multicolumn{8}{c}{ Identifying with the Capitol Insurrectionists at Time 3 (After the Outcome was } \\
Certainty & 3.47 & 66 & .39 & $<.001$ & {$[.16, .60]$} & 1.77 & 355 & .09 & .078 & {$[-.01, .20]$} \\
Belief & -.20 & 66 & -.02 & .843 & {$[-.24, .20]$} & -1.44 & 355 & -.08 & .151 & {$[-.18, .03]$} \\
\hline
\end{tabular}

Future Certainty vs. Strength of Support. To check the robustness of our findings after accounting for the strength of support for one's candidate, we reconducted the regression analyses but added strength of support (assessed at Time 1) as a control variable. Importantly, doing so did not impact the findings regarding poor information processing. Among Trump supporters, certainty that Trump would win the election (at Time 1) still predicted a higher tendency to claim that the election was rigged at Time 2 (albeit marginally this time; $\beta=.18, p=$ $.076)$ and Time $3(\beta=.39, p=.002)$. Among Biden supporters, and consistent with our previous results, certainty that Biden would win the election still predicted rigged election claims at Time 2 (before the election results were official; $\beta=.12, p=.010$ ) but not at Time 3 (after the election was officially called for Biden; $\beta=.02, p=.649$ ). Similarly, accounting for strength of support also did not change the findings regarding antisocial behavior. Future certainty that Trump would win the election still predicted endorsing violence at Time $1(\beta=.42, p<.001)$ and Time $2(\beta=$ $.25, p=.017)$ and identifying with the Capitol insurrectionists at Time $3(\beta=.25, p=.030)$. And, 
among Biden supporters, future certainty that Biden would win still predicted endorsing violence at Time $1(\beta=.12, p=.011)$ and Time 2 (albeit marginally; $\beta=.09, p=.054){ }^{8}$

\section{General Discussion}

Across three studies, certainty about the future predicted poor information processing (cognition) as well as antisocial tendencies (behavior) during two societal periods of uncertainty - the COVID-19 pandemic and the 2020 U.S. presidential election. In Study 1, certainty about positive as well as negative COVID-19 futures (e.g., "I know that everything is going be fine soon," "I know that nothing is going to get better soon") both predicted poor information processing (i.e., ignoring medical experts, adhering to conspiracy theories, lower objective knowledgeability). Building on these results, Study 2 revealed that future certainty regarding COVID-19 was linked to antisocial behaviors in terms of noncompliance with preventative health recommendations (e.g., social distancing). Finally, in Study 3, future certainty that one's preferred candidate would win the 2020 presidential election predicted poor information processing (claiming that the election was rigged when the results were inconclusive or one's candidate had lost) and greater antisocial responding (endorsing violence if one's candidate were to lose and identifying with Capital insurrectionists once one's candidate had lost).

Taken together, this work elucidates a psychological phenomenon-future certaintyand demonstrates that such certainty has meaningful and potentially dangerous cognitive and behavioral outcomes during periods of societal uncertainty.

\footnotetext{
${ }^{8}$ Strength of support for one's candidate (Biden or Trump) did not consistently predict poor information processing or antisocial behavior. For instance, while support for Trump predicted claiming that the election was rigged at Time 2 (Time $2: \beta=.22, p=.029)$ it did not do so at Time $3(\beta=.19, p=.112)$. Also, support for Trump was not related to endorsing violence at Time $2(\beta=.09, p=.400)$, although it did predict identifying with the Capitol insurrectionists at Time $3(\beta=.32, p=.008)$. See Supplementary Material A.
} 


\section{Theoretical Extensions}

The present work extends past research in several ways. First, it integrates two independent lines of research, work on certainty and work on future thought, by studying the juxtaposition of these two constructs (e.g., Oettingen, 2012; Petty \& Krosnick, 1995). While past research on certainty has almost exclusively focused on attitude certainty, that is, certainty towards relatively accessible and knowable attitude objects, the present work examined certainty about unknown future outcomes. In doing so, our work introduces future certainty as a psychological construct that - at least in cases of societal uncertainty - may have potentially deleterious consequences, including poor information processing (e.g., adopting misinformation) and antisocial behaviors (e.g., endorsing violence).

The present results not only integrate but also extend previous research on certainty and doubt, as well as research on future thinking. For instance, being certain about things that others judge as unknowable has been shown to incite antisocial responding (e.g., aggression; Gollwitzer \& Oettingen, 2019; Gollwitzer et al., 2021). The present findings align with this work by demonstrating a specific test case of this effect; certainty about the future involves certainty about content — the future — that is often perceived or judged as unknowable. Additionally, our work contributes to the literature on intellectual humility (e.g., Leary et al., 2017) by showing that intellectual doubt ("I believe that my candidate will win although I can be wrong") may be one way to effectively attenuate poor information processing and antisocial responding during uncertain societal events. Finally, the present results extend past work on the relationship between ignorance and future thinking in the form of unrealistic optimism (e.g., BlumenthalBarby \& Unel, 2018) and pessimism (e.g., Miranda \& Mennin, 2007) by showing that a strong 
conviction, regardless of its content (optimistic or pessimistic), can motivate people to ignore facts and perform uninformed behaviors.

\section{Certainty Versus Believing}

The present findings also reveal that future certainty is distinct from beliefs about the future. First, unlike future certainty, participants' beliefs about the future-which entail some doubt — did not relate to poor information processing. Instead, beliefs about negative COVID-19 futures predicted greater seeking of reliable information (e.g., attention to medical experts, less conspiratorial thinking), and beliefs about positive COVID-19 futures did not predict information processing at all. Second, while certainty about positive and negative COVID-19 futures did not correlate, beliefs about positive COVID-19 futures inversely correlated with beliefs about negative COVID-19 futures (as one would expect). These findings suggest that certainty about the future may be for the sake of certainty itself, possibly creating an experience like Orwellian doublethink where one holds contradictory forms of "knowledge" at the same time (Orwell, 1949). Third, while future certainty was generally linked to antisocial tendencies (e.g., noncompliance with COVID-19 regulations, endorsing violence, and identifying with Capital insurrectionists), beliefs about the future were not linked to such antisocial tendencies. In line with Gollwitzer and Oettingen (2019), doubt, then, may function as an important ingredient to prevent antisocial responding during periods of uncertainty.

\section{Is Future Certainty Always Dangerous?}

We focused on the potential dangers of future certainty in terms of cognition and behavior. Yet, future certainty may also have beneficial outcomes. For one, it may alleviate the negative affect (e.g., anxiety) stemming from uncertain situations (see Hirsh et al., 2012) by providing a sense of control at the moment. Further, future certainty may alleviate the cognitive 
load stemming from efforts to reduce uncertainty (e.g., collecting data from one's context; see FeldmanHall \& Shenhav, 2019). That is, future certainty can operate as a "shortcut" to certainty, namely, a computationally less expensive method of uncertainty management. Finally, future certainty may also meet some social needs by bringing together like-minded individuals (i.e., those who hold certainty about a specific future) as observed in the case of the shared reality grown among conspiracy theorists (see Sternisko et al., 2020). Future work should investigate the effects of future certainty and their underlying processes more thoroughly to better understand the psychological motives underlying future certainty.

\section{Future Certainty: Confirmed Versus Disconfirmed}

Importantly, we considered what happens when one's future certainty is later confirmed versus disconfirmed by reality. For instance, when one's future certainty is later confirmed by reality (the predicted outcome actually occurs), the links between future certainty and poor information processing and antisocial behavior may be attenuated. In Study 3, those who were certain that Biden would win the election (before the election) no longer showed poor information processing or antisocial behaviors when the outcome confirmed their certainty. At the same time, and in line with highly-committed individuals doubling down on their commitment after negative feedback (Festinger et al., 1956), supporters of Trump, whose certainty that Trump would win was later disconfirmed, continued to exhibit poor information processing and antisocial behavior. As such, the dangers of future certainty, as examined here, may be most prominent in cases where one's certainty is disconfirmed or when a direct confirmation is either unlikely or delayed (as in the case of COVID-19). Future research should continue to test such potential boundary conditions of the observed links.

\section{Limitations}


We consider several limitations. Although Study 1 was longitudinal, the high over-time consistency within the variables left us little room to reliably investigate cross-lagged effects (see Supplementary Material A). Future work may adopt a longitudinal design with longer time intervals across assessments or experimental designs. Future work should also consider the pathways underlying the observed links and whether these links exhibit reciprocal causality. For one, certainty about the future may lead to poor information processing, which in turn leads to antisocial behaviors. For another, certainty about the future may lead to poor information processing, which in turn may again foster greater certainty about the future (a cyclical process; see Dunning, 2011). Finally, we also encourage future work to examine the generalizability of our findings, for instance, in terms of testing more diverse samples and testing whether our findings remain consistent outside of societal events of uncertainty. For instance, future certainty about uncertain personal events (e.g., "I am certain I will get a promotion within the next year"), may function differently, and in turn, lead to different outcomes.

\section{Conclusion}

In three studies, certainty about the future during two major societal events of uncertainty, the COVID-19 pandemic and the 2020 U.S. presidential election, predicted important psychological outcomes across cognition and behavior. Overall, our findings suggest that certainty about the future may contribute to poor information processing and antisocial responding during periods of uncertainty. These findings open the door for a deeper scientific study of the consequences of certainty in future thinking, as well as the protective power of holding beliefs with doubt on cognizing facts, making well-informed decisions, and attenuating antisocial behavior. 


\section{References}

Abelson, R. P. (1986). Beliefs are like possessions. Journal for the Theory of Social Behaviour, $16,223-250$.

Abilov, A., Hua, Y., Matatov, H., Amir, O., \& Naaman, M. (2021). VoterFraud2020: a Multimodal dataset of election fraud claims on twitter. arXiv preprint arXiv:2101.08210.

Bandura, A. (1977). Self-efficacy: Toward a unifying theory of behavioral change. Psychological Review, 84(2), 191-215.

Blumenthal-Barby, J. S., \& Ubel, P. A. (2018). In defense of "denial": Difficulty knowing when beliefs are unrealistic and whether unrealistic beliefs are bad. The American Journal of Bioethics, 18(9), 4-15.

Brannon, L. A., Tagler, M. J., \& Eagly, A. H. (2007). The moderating role of attitude strength in selective exposure to information. Journal of Experimental Social Psychology, 43(4), 611-617.

Burton, R.A. (2008). On being certain: Believing you are right even when you're not. ( $\left.1^{\text {st }} \mathrm{ed}.\right)$. New York, NY: St. Martin’s Griffin.

Chaiken, S., Liberman, A., \& Eagly, A. H. (1989). Heuristic and systematic information processing within and beyond the persuasion context. In J. S. Uleman \& J. A. Bargh (Eds.), Unintended thought (pp. 212-252). New York: Guilford.

Chignell, A. (2021). The focus theory of hope. In N. Snow (Ed.), Hope. Oxford: OUP.

DeRose, K. (2009). The case for contextualism: Knowledge, skepticism, and context, vol. 1 (Vol. 1). Oxford University Press. 
Dieterich, R., Endrass, T., \& Kathmann, N. (2016). Uncertainty is associated with increased selective attention and sustained stimulus processing. Cognitive, Affective, \& Behavioral Neuroscience, 16(3), 447-456.

Dunning, D. (2011). The Dunning-Kruger effect: On being ignorant of one's own ignorance. In Advances in Experimental Social Psychology (Vol. 44, pp. 247-296). Academic Press.

Federico, C. M., \& Malka, A. (2018). The contingent, contextual nature of the relationship between needs for security and certainty and political preferences: Evidence and implications. Political Psychology, 39, 3-48.

FeldmanHall, O., \& Shenhav, A. (2019). Resolving uncertainty in a social world. Nature Human Behaviour, 3(5), 426-435.

Festinger, L., Riecken, H. W., \& Schachter, S. (1956). When prophecy fails. University of Minnesota Press.

Forster, N. \& Renault, M. (2020). COVID-19 viral spread related to Thanksgiving appears across U.S. PBS News Hour. https://www.pbs.org/newshour/health/covid-19-viralspread-related-to-thanksgiving-appears-across-u-s.

Gilbert, D. T., \& Ebert, J. E. J. (2002). Decisions and revisions: The affective forecasting of changeable outcomes. Journal of Personality and Social Psychology, 82(4), 503-514

Gollwitzer, A., Martel, C., Brady, W. J., Pärnamets, P., Freedman, I. G., Knowles, E. D., \& Van Bavel, J. J. (2020). Partisan differences in physical distancing are linked to health outcomes during the COVID-19 pandemic. Nature Human Behaviour, 4(11), 1186-1197.

Gollwitzer, A., \& Oettingen, G. (2019). Paradoxical Knowing, Social Psychology, 50(3), 145161. 
Gollwitzer, A., Olcaysoy Okten, I., Pizarro, A.O., \& Oettingen, G. (2021). Discordant Knowing: A social cognitive underlying fanaticism. Manuscript under review.

Hirsh, J. B., Mar, R. A., \& Peterson, J. B. (2012). Psychological entropy: A framework for understanding uncertainty-related anxiety. Psychological Review, 119(2), 304-320.

Hofstede, G. (1991). Cultures and organizations: Software of the mind. McGraw-Hill.

Kappes, A., Oettingen, G., \& Pak, H. (2012). Mental contrasting and the self-regulation of responding to negative feedback. Personality and Social Psychology Bulletin, 38(7), $845-857$.

Kristiansen, C. M., \& Harding, C. M. (1984). The social desirability of preventive health behavior. Public Health Reports, 99(4), 384-388.

Kruglanski, A. W., \& Orehek, E. (2012). The need for certainty as a psychological nexus for individuals and society. M.A. Hogg, D.L. Blaylock, M.A. Hogg, D.L. Blaylock (Eds.), Extremism and the psychology of uncertainty, pp. 1-18. Wiley-Blackwell.

Kundera, M. (1995). Slowness. Faber \& Faber.

Leary, M. R., Diebels, K. J., Davisson, E. K., Jongman-Sereno, K. P., Isherwood, J. C., Raimi, K. T., ... \& Hoyle, R. H. (2017). Cognitive and interpersonal features of intellectual humility. Personality and Social Psychology Bulletin, 43, 793-813.

Martino, J. P. (2003). A review of selected recent advances in technological forecasting. Technological Forecasting and Social Change, 70(8), 719-733.

Mellers, B., Stone, E., Atanasov, P., Rohrbaugh, N., Metz, S. E., Ungar, L., ... \& Tetlock, P. (2015). The psychology of intelligence analysis: Drivers of prediction accuracy in world politics. Journal of Experimental Psychology: Applied, 21(1), 1-14 
Miranda, R., \& Mennin, D. S. (2007). Depression, generalized anxiety disorder, and certainty in pessimistic predictions about the future. Cognitive Therapy and Research, 31(1), 71-82.

Mischel, W. (1973). Toward a cognitive social learning reconceptualization of personality. Psychological Review, 80(4), 252-283.

Mitzen, J., \& Schweller, R. L. (2011). Knowing the unknown unknowns: Misplaced certainty and the onset of war. Security Studies, 20(1), 2-35.

Niedbala, E. M., Hohman, Z. P., \& Elleby, J. S. (2018). When I'm right you're wrong: Attitude correctness facilitates anger and approach motivation toward opposing individuals. Social Influence, 13(3), 150-162.

Northington, W. M., Gillison, S. T., Beatty, S. E., \& Vivek, S. (2021). I don't want to be a rule enforcer during the COVID-19 pandemic: Frontline employees' plight. Journal of Retailing and Consumer Services, 63, 102723.

Oettingen, G. (2012). Future thought and behaviour change. European Review of Social Psychology, 23(1), 1-63.

Oettingen G. \& Chromik M. P. (2018) How hope influences goal-directed behavior. In: The Oxford handbook of hope, ed. M. W. Gallagher \& S. J. Lopez, Ch. 6, pp. 69-79. Oxford University Press.

Orwell, G. (1949). Nineteen eighty-four. Harmondsworth: Penguin.

Peeters, G., \& Czapinski, J. (1990). Positive-negative asymmetry in evaluations: The distinction between affective and informational negativity effects. European Review of Social Psychology, 1(1), 33-60.

Pennycook, G., \& Rand, D. G. (2019). Lazy, not biased: Susceptibility to partisan fake news is better explained by lack of reasoning than by motivated reasoning. Cognition, 188, 39-50. 
Pennycook, G., \& Rand, D. G. (2021). The psychology of fake news. Trends in Cognitive Sciences, 25(5), 388-402.

Petty, R. E., \& Krosnick, J. A. (Eds.). (1995). Attitude strength: Antecedents and consequences. Hillsdale, NJ: Erlbaum.

Reynolds, W. M. (1982). Development of reliable and valid short forms of the Marlowe-Crowne Social Desirability Scale. Journal of Clinical Psychology, 38(1), 119-125.

Rios, K., DeMarree, K. G., \& Statzer, J. (2014). Attitude certainty and conflict style: Divergent effects of correctness and clarity. Personality and Social Psychology Bulletin, 40, 819830.

Roozenbeek, J., Schneider, C. R., Dryhurst, S., Kerr, J., Freeman, A. L., Recchia, G., ... \& Van Der Linden, S. (2020). Susceptibility to misinformation about COVID-19 around the world. Royal Society Open Science, 7(10), 201199.

Salovich, N. A., Donovan, A. M., Hinze, S. R., \& Rapp, D. N. (2021). Can confidence help account for and redress the effects of reading inaccurate information? Memory \& Cognition, 49(2), 293-310.

Santas, G. (1990). Knowledge and belief in Plato's Republic. In Greek studies in the philosophy and history of science (pp. 45-59). Springer, Dordrecht.

Simon-Vandenbergen, A. M., \& Aijmer, K. (2008). The semantic field of modal certainty. De Gruyter Mouton.

Skitka, L. J. (2010). The psychology of moral conviction. Social and Personality Psychology Compass, 4(4), 267-281. 
Sternisko, A., Cichocka, A., \& Van Bavel, J. J. (2020). The dark side of social movements: Social identity, non-conformity, and the lure of conspiracy theories. Current Opinion in Psychology, 35, 1-6.

Thoma, V., Weiss-Cohen, L., Filkukov , P., \& Ayton, P. (2021). Cognitive predictors of precautionary behavior during the COVID-19 pandemic. Frontiers in Psychology, $12,1-17$.

Tversky, A., \& Kahneman, D. (1974). Judgment under uncertainty: Heuristics and biases. Science, 185(4157), 1124-1131.

van Prooijen, J. W. (2016). Sometimes inclusion breeds suspicion: Self-uncertainty and belongingness predict belief in conspiracy theories. European Journal of Social Psychology, 46(3), 267-279.

Weary, G., \& Jacobson, J. A. (1997). Causal uncertainty beliefs and diagnostic information seeking. Journal of Personality and Social Psychology, 73(4), 839-848.

Wegener, D. T., Petty, R. E., \& Smith, S. M. (1995). Positive mood can increase or decrease message scrutiny: The hedonic contingency view of mood and message processing. Journal of Personality and Social Psychology, 69(1), 5-15.

Wonacott, S. (2020). Traveling over Thanksgiving? Here are the states with restrictions on travel. Ballotpedia News. https://news.ballotpedia.org/2020/11/24/traveling-overthanksgiving-here-are-the-states-with-restrictions-on-travel/. 